\title{
CHILDREN BORN SMALL FOR GESTATIONAL AGE ARE NOT AT SPECIAL RISK FOR PRESCHOOL EMOTION AND BEHAVIOUR PROBLEMS
}

Christine M. Cornforth ${ }^{1,2}$, John M.D. Thompson ${ }^{1}$, Elizabeth Robinson ${ }^{3}$, Karen E. Waldie ${ }^{4}$, Jan E. Pryor ${ }^{5}$, Philippa Clark ${ }^{1}$, David M.O. Becroft ${ }^{1}$, Edmund J.S. Sonuga-Barke ${ }^{2,6}$, Edwin A. Mitchell ${ }^{1}$

${ }^{1}$ Department of Paediatrics: Child and Youth Health, University of Auckland, NZ

${ }^{2}$ Institute for Disorders of Impulsivity and Attention, School of Psychology, University of Southampton, UK

${ }^{3}$ School of Population Health, University of Auckland, NZ

${ }^{4}$ Department of Psychology, University of Auckland, NZ

${ }^{5}$ McKenzie Centre for the Study of Families, Victoria University, Wellington, NZ

${ }^{6}$ Department of Experimental Clinical \& Health Psychology, Ghent University, Belgium.

* Corresponding author:

Professor E A Mitchell

Department of Paediatrics

University of Auckland

New Zealand

Direct tel: +44 (0)23 80599677

Direct fax: +44 (0)238059 4597

email: e.mitchell@auckland.ac.nz 


\section{ABSTRACT}

Despite the wealth of literature examining long term outcomes of preterm low birthweight children, few studies have directly assessed the developmental impact of being born full term but small for gestational age (SGA). We aim to determine whether (i) being SGA increases preschool behavioural problems and (ii) other risk factors operate differently in SGA and appropriate for gestational age (AGA) controls. 550 New Zealand European mothers and their 3.5 year old children participated in this study. All children were born at full term $(>37$ weeks' gestation) and approximately half were SGA $\left(\leq\right.$ sex specific $10^{\text {th }}$ percentile for gestation) the remainder were AGA controls. Extensive data were collected at the child's birth, 1 year and 3.5 years. Behavioural problems were measured when children were 3.5 years, using the Strengths and Difficulties Questionnaire (SDQ). Multiple regression analyses were used to examine the associations between risk factors and behavioural problems; statistical weighting was used for analyses of the total study group. There was no significant difference in behavioural problems between SGA and AGA groups. In the total sample the significant predictors of behavioural problems included: mothers' school leaving age; smoking during pregnancy; maternal alcohol use during pregnancy; and absence of the father. Predictors of behavioural problems were found to be the same for SGA and AGA groups. These results do not support the view that SGA is a risk for behavioural preschool difficulties or that SGA children are sensitized to risks known to be associated with such difficulties in the preschool years.

Key words: preschool children, emotion, behaviour, risk factors, strengths and difficulties questionnaire, small for gestational age 
Cornforth et al., Determinants of Emotional and Behavioural Difficulties in SGA Children

Abbreviations: SDQ (Strengths and Difficulties Questionnaire), SGA (small for gestational age), AGA (appropriate for gestational age), ABC (Auckland Birthweight Collaborative) 


\section{INTRODUCTION}

Behaviour and emotional problems are of particular concern in the preschool age group as once established they often persist throughout childhood and adolescence and, in some cases, continue into young adulthood $(1,2)$. The prevalence rates of these problems vary between $10 \%$ and $20 \%(3,4)$ with between study differences in estimates due to the limitations of diagnostic tools used to classify problem behaviour. Gathering prevalence estimates for this age group is complicated as the preschool developmental period is one of the most challenging in terms of defining and measuring psychiatric symptomatology. On the whole, the literature suggests that externalising problems (e.g., hyperactivity, impulsivity, and oppositional defiant symptoms) are more prevalent in males $(5,6)$, and internalising problems (e.g., phobias, anxiety and depression) are more prevalent in females (7).

Childhood emotional and behavioural problems, particularly in the preschool years, are multi-factorial in determination. Socio-demographic factors include young maternal age (8), limited parental education (9), low socio-economic status (4) and low levels of social support (10). Furthermore, perinatal exposures to nicotine (11), alcohol (12) and stress (13) are also important. Some of the strongest support is for prematurity (14-19) and/or being small for gestational age (SGA:14, 19, 20,21) both of which have been related to the onset of childhood disorders such as $\operatorname{ADHD}(22,23)$, anxiety and depression (24) and learning difficulties (25). Understanding these particular associations is complicated as both are linked to (i) a suboptimal prenatal environment (which is often as a result of foetal exposure to one or more of the factors previously described), and (ii) prematurity and SGA are often combined in studies of the risks associated with low birthweight. The hypothesis that SGA effects should operate independently of prematurity and therefore constitute a distinct risk factor is based on the concept of intra uterine growth restriction (IUGR). One possible cause 
of IUGR is when a foetus does not receive enough oxygen or nutrients during pregnancy, and as a consequence their overall body and organ growth is limited. Many factors have been found to be associated with SGA and/or IUGR including; low maternal pre pregnancy weight $(26,27)$, maternal smoking during pregnancy $(28,29)$ and maternal hypertension (29). In addition, genetics have also been found to be involved in both IUGR and being born SGA (for a review see 30). It is unclear exactly how poor intra uterine growth affects the foetal brain to cause psychopathology. One possibility is that there is a restriction in blood flow through the placenta which results in IUGR. This in turn causes the foetus to receive less oxygen than would normally be expected, increasing the risks to the foetus during pregnancy, delivery, and afterwards. Furthermore, such foetal hypoxia can result in damage to catecholamine receptors in the brain (e.g., dopamine; 31, 32).

To date, only one study has investigated the behavioural development of full term SGA (33). (The definition of full term is important as it rules out the possibility that the child's birthweight is a consequence of prematurity factors). Sommerfelt and colleagues (33) studied a relatively large group of SGA $(n=318)$ and AGA $(n=307) 5$ year old children and found behavioural problems were not more common among the SGA children. Furthermore, being born SGA was not found to make an individual more sensitive to the negative impact of common risk factors (33). The present study extends this research in similar size sample of full term SGA and AGA preschool children in a study with a longitudinal cohort design. This has allowed for the collection of a number of risk factors at different points throughout the child's development. Here we aim to: (1) to determine whether SGA children are at increased risk for emotional and behavioural problems compared with AGA children; and (2) to examine whether the risk profile for SGA children is different to that of AGA children, and 
Cornforth et al., Determinants of Emotional and Behavioural Difficulties in SGA Children

if not we also aim to examine the prevalence and risk profile for the total study group using statistical weighting to allow for the complex weighting design. 


\section{METHODS}

The Auckland Birthweight Collaborative (ABC) study is a longitudinal cohort with disproportionate sampling. The methodology for phases one to three of the ABC study has previously been described in detail (29). Participants are mothers and their singleton infants were born full term in the Auckland and Waitamata Healthcare regions, between 16 October1995 and 30 November 1997. Approximately half of the infants were SGA with birthweights equal to or below the sex-specific tenth percentile for gestation, and the remainder were a random sample of infants born AGA (34). Infants were excluded from the study if they were born outside a designated study region, were from multiple births or had congenital abnormalities likely to affect growth or development.

Data collection has occurred in three phases: phase one, birth; phase two, 1 year; and phase three, 3.5 years. Extensive psychological, developmental, social and physical data were collected for children and their families at all phases. Due to the differential in response rates from ethnic groups at earlier phases, this study has been restricted to New Zealand European mothers and their infants. There were 871 New Zealand European mothers and infants enrolled at birth who were eligible to take part at 3.5 years; of these $550(63 \%)$ were successfully followed up when children were aged 3.5 years. Complete SDQ scores were available for 538 children $(\mathrm{SGA}=225, \mathrm{AGA}=313)$.

Factors associated with attrition at phase three have previously been reported in detail (35). In summary, respondents were more likely to be older, married, of high socio-economic status, have tertiary education, and be non-smokers. Respondents and non respondents did not differ in gestational age, birthweight, infant sex, parity and levels of family social support or maternal stress. 


\section{Outcome Measure}

Child behaviour was measured at phase three using the parent format of the Strengths and Difficulties Questionnaire (SDQ; 36). SDQ is a 25 item scale which asks about both positive and negative emotional and behavioural attributes on 5 subscales - conduct, emotion, hyperactivity-inattention, peer group relationships and pro-social behaviour. Each item is scored on a 3 point Likert scale of $0=$ 'not true', $1=$ 'somewhat true' and $2=$ 'certainly true'. The total scores for each subscale are calculated by summing scores on items relevant to a particular problem, for example the hyperactivity-inattention subscale consists of items such as 'restless, overactive, cannot stay still for long' (range $=0-10)$. The SDQ also provides a total difficulties score (range $=0-40$ ) which is calculated by summing all subscale scores except pro-social (as the authors suggest the presence of pro-social behaviours is considered to be conceptually different to the absence of other behaviours). The SDQ has a good test-retest stability and the internal consistencies of the subscales range from 0.62 to 0.75 (37). Cut-off points used in this study to define 'normal', 'borderline' and 'abnormal' scores were taken from UK norms published on the SDQ website

(www.sdqinfo.com). This study focused on the prediction of the total behavioural difficulties subscale because of the greater reliability of the total difficulties scale compared with the individual subscales (which are defined by 5 items). In this study children were defined as having an abnormal behavioural total difficulties score if they had a total difficulties score in the abnormal or borderline range. At phase three of the study SDQ data were collected for 538 children.

\section{Measurement of risk factors}

(i) Maternal Perceived Stress. This was measured at phases one and three using the 10-item Perceived Stress Scale (38). This scale was designed to measure the degree to which 
situations in life are appraised as stressful. We created a categorical variable using a $75^{\text {th }}$ percentile cut off, scores that fell above this were considered as high.

(ii) Social support. The Family Support Scale (39) measures different sources of support for families rearing a young children. This variable was examined categorically with low levels of social support defined by a total score that was less than or equal to the $25^{\text {th }}$ percentile of scores in this study.

(iii) Parental smoking and maternal alcohol use during pregnancy. Smoking data were collected at birth and coded as a dichotomous variable ('yes' or ' $n o$ ') for mothers who reported having smoked the year before pregnancy and fathers who smoked up to the time of the child's birth. Maternal alcohol consumption during pregnancy was recorded at the time of the child's birth and coded as 'no alcohol', '1 - 7 units of alcohol per week', and '>7 units of alcohol per week'.

(iv) Child activity level. At phase three, parents were asked if their child was more active, less active or had the same levels of activity compared with other children of the same age. The 'increased activity level' and 'same activity level' categories were combined as there were no significant differences in risk of emotional and behavioural difficulties between the groups.

(v) Demographic factors. Data on a child's sex, parental marital status, maternal school leaving age and maternal age at the child's birth was collected at the time of the child's birth (phase one).

Ethical approval was obtained from the North Health Regional Ethics Committee. 


\section{Statistical Analyses}

The difference in prevalence of emotional and behavioural problems between SGA and AGA groups was examined using chi-square. The association of problems with potential risk factors was studied at all phases of the study using simple and multiple regression analyses. In order to examine whether the association between a particular risk factor and behavioural problems differed between SGA and AGA groups, an interaction term was included in the analyses. Evidence of a significant interaction was determined at a $5 \%$ level.

Odds ratios (OR) from simple and multiple logistic regressions are presented for each category of a variable in relation to a reference category. Chi-square values and $p$-values for the overall effect of variables in the model are also given.

Multiple regression analyses adjusted for the potentially confounding effects of a child's sex, parental marital status, maternal school leaving age and maternal age at the child's birth. These variables were selected as there were 'a priori' reasons to expect that they would be associated with the occurrence of emotional and/or behavioural problems. Variables identified from previous studies as likely to be associated with the occurrence of behavioural problems in children that were found to be significant at a $10 \%$ level in simple regression analyses, were added to this base model in groups according to the data collection phase. Firstly, variables measured at the time of the child's birth were added to the model; those that continued to be significant at a 5\% level remained in the model, however, those that were no longer significant were removed from the model. Following this, we used the same approach when adding variables that were collected when children were age 1 and 3.5 years to the model. The final multiple regression model provides an odds ratio for each variable which adjusts for the effects of all other variables in the model. An overall $p$-value of 0.05 or less was considered to be evidence of statistical significance. 
Cornforth et al., Determinants of Emotional and Behavioural Difficulties in SGA Children

Where estimates have been calculated for the total group, weighted logistic regression was used. Analyses were calculated in SAS v9.1 (SAS 2004). 


\section{RESULTS}

No significant difference in the rate of emotional and behavioural problems between SGA and AGA groups was found $\left(\mathrm{SGA}=17.8 \%, \mathrm{AGA}=17.9 \% ;\left(\chi^{2}(1)=1.02, p=0.31\right)\right.$. In the total weighted sample, the prevalence of an abnormal total difficulties score was $18.9 \%$.

Table 1 presents the unadjusted and adjusted regression results for the total weighted sample. Variables of interest that met the inclusion criteria $(\mathrm{p}>0.10)$ in unadjusted analyses and continued to be predictive ( $p>0.05$ ) of behavioural problems in adjusted analyses included: current maternal stress (when the child was age 3.5 years), maternal smoking prior to pregnancy, paternal smoking at the time of pregnancy, maternal alcohol use in the first month of pregnancy, whether or not the child's biological father was currently living in the family home (when the child is age 3.5 years) and child activity level at age 3.5 years.

Table 2 reports the frequencies of abnormal SDQ scores for the SGA and AGA groups separately with interactions between the key risk variables and SGA/AGA status. Given that no significant interactions were present, (meaning that the association of risk factors with behavioural problems were not found to be different for the SGA and AGA groups), all subsequent analyses are presented for the total weighted sample.

Mothers who left school when they were younger than age 16 years were found to be over four times more likely to have a child with an abnormal total difficulties score at age 3.5 years $(\mathrm{OR}=4.42,95 \% \mathrm{CI}=1.53-12.76)$ than those mothers who left school at 16 years of age or older. In an adjusted analysis, maternal stress when the child was aged 3.5 years continued to be predictive of abnormal total difficulties, yet maternal social support at 3.5 years no longer remained statistically significant. Maternal stress and social support measured at the time of the child's birth were not found to be significantly associated with an abnormal 
total difficulties score $(\mathrm{p}>0.05)$, however maternal social support was found to be of borderline significance $(\mathrm{p}=0.06)$.

Children of mothers who reported having smoked regularly prior to pregnancy were found to be twice as likely for their child to have an abnormal total difficulties score at age 3.5 years $(\mathrm{OR}=2.01,95 \% \mathrm{CI}=1.06-4.15)$ than those mothers who did not smoke prior to pregnancy. Furthermore, children of fathers who smoked at the time of their birth were also found to be more than twice as likely to have an abnormal total difficulties score at age 3.5 years than children whose fathers did not smoke at this time $(\mathrm{OR}=2.21,95 \% \mathrm{CI}=1.04-$ 4.15). Mothers who consumed more than 7 units of alcohol per week in the first month of pregnancy were found to be over six times more likely to have a child with an abnormal total difficulties score 3.5 years later $(\mathrm{OR}=6.13,95 \% \mathrm{CI}=1.73-21.65)$.

Children with high activity levels at age 3.5 years were over twice as likely to have an abnormal total difficulties score than children whose activity levels were normal to low $(\mathrm{OR}=2.13,95 \% \mathrm{CI}=1.06-4.31)$. Finally, children who did not live with their biological father when they were aged 3.5 years were found to be three times more likely to have behavioural problems compared with children whose biological father lived in the family home $(\mathrm{OR}=3.11,95 \% \mathrm{CI}=1.09-8.89)$. 


\section{DISCUSSION}

The current findings replicated the Sommerfelt et al., paper (33) in (1) finding no significant difference in emotional and behavioural problems between SGA (17.8\%) and AGA (17.9\%) children, suggesting that SGA is not associated with an increased risk of behavioural problems in the preschool years; and (2) the risk profile for SGA children was not found to be different to that of AGA children. Although we did establish independent associations for a range of prenatal biological factors and postnatal factors, these operated in a similar way in both groups - (i.e. SGA did not sensitize children to these risk factors). This suggests that previous findings showing a link between SGA and behavioural problems may be the result of prematurity or other factors with which SGA is confounded and which have not always been well controlled for statistically.

Studies that have highlighted differences in the rates of emotional and/or behavioural problems between SGA and AGA groups have focused mainly on infants (40) and adolescents (41), with few examining the developmental period between these age groups (i.e., preschool and school age). The developmental period from preschool through to school age is an important time as this is a time when there are a number of critical periods for the development of key skills and abilities, such as language, emotional regulation, self regulation, social adjustment and moral realism. Secondly, the majority of studies in this area have been limited by small sample sizes and the use of non standardised definitions for SGA status. Here, we employed a relatively large sample of SGA children defined as such using the tenth percentile of sex specific birthweight percentiles by gestational age based on the New Zealand population. Finally, there are few studies that employ population based designs. 
The current study findings refute the idea that poor IUGR growth affects the foetal brain and in turn causes psychopathology up to the preschool years. It is possible that subtle pathophysiologic alterations during brain development may result from factors that affect growth in utero and as the brain develops and matures over the course of childhood, such alterations could affect child behaviour.

Of the factors shown to be important for the whole sample there were a number of striking findings. In line with other studies in the literature we found that children of mothers who had limited education were more likely to have behavioural difficulties $(8,9)$. Young mothers encounter greater risks themselves and for their children as they can be less affectionate and nurturing than older mothers and less likely to stimulate their children verbally and cognitively (8). Furthermore, these mothers are often of low socio-economic status and are therefore more likely to have poor nutrition and lack social support (42). Callaghan (1999) suggests that limited maternal education, regardless of age, is a risk factor for child behavioural problems, as it directly affects the quality of parenting. For example, maternal 'cognitive readiness' for parenting (defined as knowledge of child development, parenting style preferences and parenting attitudes) has been found to directly impact a child's tendency to have behavioural problems (43). Despite this, it has been suggested that maternal age and education level may not directly cause children's behavioural problems, as the disadvantage of children born to younger mothers has been shown to be reduced when the effects of maternal family background are controlled (44). Although measures of maternal family background were not explicitly collected in this study, the association between young maternal age and limited education on preschool behavioural difficulties remained, after controlling for a number of factors related to family socio-demography. 
It is not surprising that mothers with high stress levels when their children were aged 3.5 years were found to be more likely for their child to have emotional and/or behavioural problems at this age - compared with mothers who had normal to low levels of stress at this time. The continued adverse effects of parental stress on child psychopathology have been documented previously in the literature (45-48). It is possible that other adverse circumstances that have been found to contribute to maternal stress (e.g., socioeconomic disadvantage (48), parental psychopathology (49), poor parent - child relationship (50) and family discord (51), can also contribute to child psychopathology: therefore determining the underlying cause can become difficult. Nonetheless, these results further support the notion that mothers who are stressed are at greater risk of having children who become stressed, discontent and insecure (45).

Here, we also report an association between child behavioural problems and parental marital status. Children who were born to single mothers were more likely to have behavioural problems at 3.5 years of age than children of married parents. This association did not remain statistically significant after controlling for the effects of additional sociodemographic factors (e.g., maternal age and education). Nonetheless, this finding supports the view that single mothers are likely to also experience financial difficulties, a lack of self esteem and low levels of social support and that such difficulties can lead to a less conducive environment for their children to develop (10).

The findings of this study emphasize the importance of paternal factors on preschool behavioural development; in particular the absence of a child's biological father from the home environment in the preschool years. Paternal absence has long been associated with adverse child behavioural outcomes, and factors such as economic stressors related to single parenthood, perceptions of abandonment or guilt by the child, and continuing marital conflict 
have been argued to be contributory factors (52). A recent study, however, reported that the effects of being raised by biological parents, particularly fathers, depend upon the quality of care parents can provide, and in situations where fathers demonstrated antisocial behaviour, it was more beneficial to the child's behavioural development to live in single-parent families than to live with both parents (53).

We have found that children born to mothers who reported consuming more than seven units of alcohol per week in the first month of pregnancy were more likely to have behavioural difficulties at age 3.5 years than mothers who consumed less than seven units of alcohol. This finding remained statistically significant after controlling for the effects of confounding variables (including maternal smoking) in the final regression model. Children who are prenatally exposed to the effects of alcohol are at an increased risk for psychiatric disorders in later childhood (12) and are more likely to be rated as hyperactive, disruptive, impulsive or delinquent (54). Adverse effects of prenatal alcohol exposure on child behaviour in the school aged years have been reported to be evident even at low levels of exposure (i.e., one alcoholic beverage a week), and have showed dose-response effects (12). A number of physiological, environmental, and genetic pathways that link maternal substance use to children's behavioural outcomes have been put forward (55). Firstly, maternal substance use during pregnancy may affect a developing child's emotional and behavioural outcomes through teratogenic processes. Secondly, it is possible that maternal substance use could disrupt the family home environment or parenting in a way that leads to the development of a child's behavioural problems. Finally, mothers and their children may share a genetic vulnerability to substance use and other types of problem behaviours. These three pathways are not mutually exclusive; they are likely to overlap (55). Establishing a causal relationship between factors such as maternal alcohol use or smoking during pregnancy and later 
behavioural problems in offspring is not a straightforward task. An observed positive association may not be causal as it is possible that unobserved factors that are correlated with maternal alcohol use and smoking and a child's emotional or behavioural outcomes are present. For example, if a mother suffers from chronic anxiety or depression, this may lead both to maternal substance use and to emotional or behavioural problems in her child. It is therefore important to interpret these results with caution, as this study did not control for factors such as maternal psychopathology.

This study also found an association between paternal smoking and child behavioural problems. This association remained strong after controlling for the effects of covariates such as maternal smoking and other socio demographic factors; however, it remains difficult to untangle the possible biological and socio-demographic mechanisms that might explain this relationship. As Weissman and colleagues suggest, if parental smoking was a marker for genetically driven behavioural problems in children, studies would have found that both maternal and paternal smoking contribute equally to adverse outcomes in children and this has not been the case (11). The majority of studies have found that maternal smoking is more strongly associated with adverse developmental outcomes than paternal smoking with the exception of one study, which has recently reported that paternal smoking (and not maternal smoking) had a negative effect on attentional control in children with ADHD. This effect appeared to be mediated by genetic risk factors (56). It is possible that the significant effects of paternal smoking at the time of the child's birth reported here are related to either personality or psychosocial factors associated with fathers / men who smoke. For example, there is evidence that cigarette smoking is over-represented in men who are arrested for domestic violence, and that violent men who smoke cigarettes are more likely to abuse other substances than those who do not smoke (57). This group of men are also more likely to 
experience psychopathology, impulsivity, anger and criminality (58). It may be that nicotine dependence can serve as a marker for these other characteristics and that the significant association between paternal smoking and child emotional and behavioural problems found in this study provides evidence of a genetic transmission of psychopathology.

Findings from this study support previous evidence that sex differences in problem behaviours are not as marked in the preschool years as they are reported to be for children of older ages (59), despite evidence to suggest that sex differences in problem behaviour in the preschool years are apparent (60).

The present study has a number of strengths. It contains a relatively large number of participants in the total study population, including a good number of SGA children. This has allowed for investigations of the differences in risk factors between the two groups. The $\mathrm{ABC}$ study dataset also includes a wide range of variables (including key biological and socio-demographic determinants) that can be examined in relation to the occurrence of emotional and behavioural problems in childhood. Despite this, a potential limitation of this study is that the sample consisted predominantly of well-educated, middle and high socioeconomic status, New Zealand European mothers and their children. Therefore, the results may not be generalisable to non-European ethnic groups. Furthermore, the SDQ cannot be considered a full assessment of a child's emotional and behavioural difficulties in the preschool years. Future research should include multiple methods of assessment (such as observational assessments of the child and the parent-child relationship) to ensure that accurate estimates of early problems are obtained.

These results support the hypothesis that there are diverse pathways through which factors such as young parenthood, limited maternal education and single parenthood 
influence subsequent child behaviour (61). We found that factors associated with preschool behavioural problems are related more to the social and lifestyle context of the family and less to characteristics that relate directly to the child, such as birthweight. It has not been possible to attribute complete causality to one environmental risk factor or another from the current findings, nor are we able to explain why some children appear to be vulnerable to adversity while others are resilient. One possible method of investigating these issues further is by looking at the role of gene - environment interactions, which would allow the examination of effects of specific prenatal influences (such as birthweight) together with genetic and/or postnatal environmental factors on the development of behavioural problems later in life (23).

\section{Clinical Implications}

It is important to understand the factors that place children at risk of significant mental health problems when planning prevention and early intervention strategies. One of the most significant protective factors in preventing the development of a mental health problem in childhood is socioeconomic security. Despite evidence suggesting that reducing socioeconomic disadvantage has no effect on child psychiatric morbidity (62), this study recommends that continued efforts to reduce socio-economic disadvantage could potentially provide the right 'social context' for the development of policies and programs that are targeted towards reducing psychiatric disorders in young children. The findings of this study highlight the need for routine screening in paediatric primary care settings to identify preschool children and families who may benefit from early intervention services and to prevent continued difficulties in later childhood. Finally, it is critical to increase awareness about early-emerging psychopathology among professionals who are working with parents of very young children in order to promote early identification. 


\section{Acknowledgements}

The initial study was funded by the Health Research Council of New Zealand (HRC). The 12 month postal questionnaire was funded by the Hawkes Bay Medical Research Foundation. The 3.5 year assessment was funded by the Child Health Research Foundation, Becroft Foundation and Auckland Medical Research Foundation and took place in the Children's Research Centre which is supported by the Starship Foundation and Auckland HealthCare Ltd. E.A. Mitchell and J.M.D. Thompson are supported in part by the Child Health Research Foundation. We would like to thank sincerely the children and families who have participated and those responsible for data collection (Dr. Rebecca Slykerman, Gail Gillies and Helen Nagels). 


\section{References}

1. Stevenson J, Goodman R. Association between behaviour at age 3 years and adult criminality. British Journal of Psychiatry. 2001;179(SEPT.):197-202.

2. Moffitt TE. Juvenile delinquency and attention deficit disorder: boys' developmental trajectories from age 3 to age 15. Child Development. 1990 Jun;61(3):893-910.

3. Meltzer H, Gatward R, Goodman R, Ford T. The Mental Health of Children and Adolescents in Great Britain. London: The Stationary Office; 2000.

4. Lavigne JV, Gibbons RD, Christoffel KK, Arend R, Rosenbaum D, Binns H, et al. Prevalence rates and correlates of psychiatric disorders among preschool children. Journal of the American Academy of Child \& Adolescent Psychiatry. 1996 Feb;35(2):204-14.

5. Holling H, Kurth BM, Rothenberger A, Becker A, Schlack R, Holling H, et al. Assessing psychopathological problems of children and adolescents from 3 to 17 years in a nationwide representative sample: results of the German health interview and examination survey for children and adolescents (KiGGS). European Child \& Adolescent Psychiatry. 2008 Dec;17 Suppl 1:34-41.

6. Rydell AM, Diamantopoulou S, Thorell LB, Bohlin G. Hyperactivity, shyness, and sex: Development and socio-emotional functioning. British Journal of Developmental Psychology. 2009;27:625-48.

7. Olson SL, Rosenblum K. Preschool Antecedents of Internalizing Problems in Children Beginning School: The Role of Social Maladaptation. Early Education \& Development. 1998;9(2):117 - 29. 
8. McAnarney ER, Lawrence RA. Day care and teenage mothers: nurturing the motherchild dyad. Pediatrics. 1993 Jan;91(1 Pt 2):202-5.

9. Kahn RS, Wilson K, Wise PH. Intergenerational health disparities: socioeconomic status, women's health conditions, and child behavior problems. Public Health Reports. 2005 Jul-Aug;120(4):399-408.

10. Crnic K, Greenberg M, Ragozin A, Robinson N, Basham R. Effects of stress and social support on mothers and premature and full term infants. Child Development. 1983;54:209 - 17.

11. Weissman MM, Warner V, Wickramaratne PJ, Kandel DB. Maternal smoking during pregnancy and psychopathology in offspring followed to adulthood. Journal of the American Academy of Child \& Adolescent Psychiatry. 1999 Jul;38(7):892-9.

12. Sood B, Delaney-Black V, Covington C, Nordstrom-Klee B, Anger J, Templin T, et al. Prenatal Alcohol Exposure and Childhood Behaviour at Age 6 to 7 Years: I DoseResponse Effects. Pediatrics. 2001;108(2):E34.

13. O'Connor TG, Heron J, Golding J, Glover V. Maternal antenatal anxiety and behavioural/emotional problems in children: a test of a programming hypothesis. Journal of Child Psychology \& Psychiatry \& Allied Disciplines. 2003 Oct;44(7):1025-36.

14. Linnet KM, Wisborg K, Agerbo E, Secher NJ, Thomsen PH, Henriksen TB. Gestational age, birth weight, and the risk of hyperkinetic disorder. Archives of Disease in Childhood. 2006;91(8):655-60. 
15. Bhutta AT, Cleves MA, Casey PH, Cradock MM, Anand KJS. Cognitive and behavioral outcomes of school-aged children who were born preterm - A meta-analysis. Jama-Journal of the American Medical Association. 2002;288(6):728-37.

16. McCormick MC, WorkmanDaniels K, BrooksGunn J. The behavioral and emotional well-being of school-age children with different birth weights. Pediatrics. 1996;97(1):18-25.

17. Mick E, Biederman J, Prince J, Fischer MJ, Faraone SV. Impact of low birth weight on attention-deficit hyperactivity disorder. Journal of Developmental and Behavioral Pediatrics. 2002;23(1):16-22.

18. Indredavik MS, Skranes JS, Vik T, Heyerdahl S, Romundstad P, Myhr GE, et al. Low-birth-weight adolescents: Psychiatric symptoms and cerebral MRI abnormalities. Pediatric Neurology. 2005;33(4):259-66.

19. Indredavik MS, Vik T, Heyerdahl S, Kulseng S, Fayers P, Brubakk AM. Psychiatric symptoms and disorders in adolescents with low birth weight. Archives of Disease in Childhood Fetal \& Neonatal Edition. 2004 Sep;89(5):F445-50.

20. Wiles NJ, Peters TJ, Heron J, Gunnell D, Emond A, Lewis G, et al. Fetal growth and childhood behavioural problems. American Journal of Epidemiology. 2006;163(11):S18-S.

21. Lahti J, Raikkonen K, Kajantie E, Heinonen K, Pesonen AK, Jarvenpaa AL, et al. Small body size at birth and behavioural symptoms of ADHD in children aged five to six years. J Child Psychol Psychiatry. [Article]. 2006 Nov;47(11):1167-74.

22. Rice F, Jones I, Thapar A. The impact of gestational stress and prenatal growth on emotional problems in offspring: a review. Acta Psychiatrica Scandinavica. 2007;115(3):17183. 
23. Schlotz W, Phillips DIW. Fetal origins of mental health: Evidence and mechanisms. Brain Behavior and Immunity. 2009;23(7):905-16.

24. Hack M, Youngstrom EA, Cartar L, Schluchter M, Taylor HG, Flannery D, et al. Behavioral outcomes and evidence of psychopathology among very low birth weight infants at age 20 years. Pediatrics. 2004;114(4):932-40.

25. Taylor HG, Klein N, Minich NM, Hack M. Middle-school-age outcomes in children with very low birthweight. Child Development. [Article]. 2000 Nov-Dec;71(6):1495-511.

26. Leffelaar ER, Vrijkotte TGM, van Eijsden M. Maternal early pregnancy vitamin D status in relation to fetal and neonatal growth: results of the multi-ethnic Amsterdam Born Children and their Development cohort. Br J Nutr. [Article]. Jul;104(1):108-17.

27. Thompson JMD, Wall C, Becroft DMO, Robinson E, Wild CJ, Mitchell EA. Maternal dietary patterns in pregnancy and the association with small-for-gestational-age infants. $\mathrm{Br} \mathbf{J}$ Nutr. [Article]. Jun;103(11):1665-73.

28. Okah FA, Hoff GL, Dew PC, Cai J. Ponderal Index of the Newborn: Effect of Smoking on the Index of the Small-for-Gestational-Age Infant. American Journal of Perinatology. [Article]. May;27(5):353-60.

29. Thompson J, Clark P, Robinson E, Becroft D, Patterson N, Glavish N, et al. Risk Factors for Small-For-Gestational-Age Babies: The Auckland Birthweight Collaborative Study. Journal of Pediatrics and Child Health. 2001;37:369 - 75.

30. Infante-Rivard C. Studying genetic predisposition among small-for-gestational-age newborns. Semin Perinatol. 2007 Aug;31(4):213-8. 
31. Palmer AA, Brown AS, Keegan D, Siska LD, Susser E, Rotrosen J, et al. Prenatal protein deprivation alters dopamine-mediated behaviors and dopaminergic and glutamatergic receptor binding. Brain Res. 2008 Oct 27;1237:62-74.

32. Stanwood GD, Levitt P. Prenatal exposure to cocaine produces unique developmental and long-term adaptive changes in dopamine D1 receptor activity and subcellular distribution. J Neurosci. 2007 Jan 3;27(1):152-7.

33. Sommerfelt K, Andersson HW, Sonnander K, Ahlsten G, Ellertsen B, Markestad T, et al. Behavior in term, small for gestational age preschoolers. Early Human Development. 2001;65(2):107-21.

34. Thompson JM, Mitchell EA, Borman B. Sex specific birthweight percentiles by gestational age for New Zealand. New Zealand Medical Journal. 1994 Jan 26;107(970):1-3.

35. Slykerman RF, Thompson JMD, Becroft DMO, Robinson E, Pryor JE, Clark PM, et al. Breastfeeding and intelligence of preschool children. Acta Paediatrica, International Journal of Paediatrics. 2005 Jul;94(7):832-7.

36. Goodman R. The extended version of the Strengths and Difficulties Questionnaire as a guide to child psychiatric caseness and consequent burden. Journal of Child Psychology and Psychiatry and Allied Disciplines. 1999;40(5):791 - 9.

37. Goodman R. Psychometric Properties of the Strengths and Difficulties Questionnaire. Journal of American Child Adolescent Psychiatry. 2001;40(11):1337 - 45.

38. Cohen S, Kamarck T, Mermelstein R. A global measure of perceived stress. Journal of Health and Social Behaviour. 1983;24:385 - 96. 
39. Dunst C, Jenkins V, Trivette C. The Family Support Scale: Reliability and Validity. Journal of Individual, Family and Community Wellness. 1984;1(4):45-52.

40. Figueras F, Oros D, Cruz-Martinez R, Padilla N, Hernandez-Andrade E, Botet F, et al. Neurobehavior in term, small-for-gestational age infants with normal placental function. Pediatrics. 2009 Nov;124(5):e934-41.

41. Pryor J, Silva PA, Brooke M. Growth, development and behavior in adolescents born small for gestational age. . Journal of Paediatrics and Child Health. 1995 Oct;31(5):403-7.

42. Johnson J, Primas P, Coe M. Factors That Prevent Women of Low Socioeconomic Status From Seeking Prenatal Care. Journal of the American Academy of Nurse Practitioners. 1994;6(3):105 -11.

43. Callaghan M, Borkowski J, Whitman T, Maxwell S, Kehoe D. A model of adolescent parenting: The role of cognitive readiness to parent. Journal of Research on Adolescence. 1999;9(2):203 - 25.

44. Sommer K, Whitman T, Borsowsk J, Schellenbach C. Cognitive Readiness and Adolescent Parenting. Developmental Psychological. American Psychological Association. 1993;29(2):389 - 98.

45. Bakoula C, Kolaitis G, Veltsista A, Gika A, Chrousos GP. Parental stress affects the emotions and behaviour of children up to adolescence: A Greek prospective, longitudinal study. Stress. [Article]. 2009;12(6):486-98.

46. Hackett R, Hackett L. Child psychiatry across cultures. International Review of Psychiatry. 1999;11(2-3):225-35. 
47. Fleitlich B, Goodman R. Social factors associated with child mental health problems in Brazil: cross sectional survey. British Medical Journal. 2001;323(7313):599-600.

48. Goodman A, Fleitlich-Bilyk B, Patel V, Goodman R. Child, family, school and community risk factors for poor mental health in Brazilian schoolchildren. Journal of the American Academy of Child and Adolescent Psychiatry. 2007;46(4):448-56.

49. Nomura Y, Wickramaratne PJ, Warner V, Mufson L, Weissman MM. Family discord, parental depression, and psychopathology in offspring: Ten-year follow-up. Journal of the American Academy of Child and Adolescent Psychiatry. 2002;41(4):402-9.

50. Olson SL, Bates JE, Sandy JM, Lanthier R. Early developmental precursors of externalizing behavior in middle childhood and adolescence. Journal of Abnormal Child Psychology. 2000;28(2):119-33.

51. Cummings EM, Goeke-Morey MC, Papp LM, Dukewich TL. Children's responses to mothers' and fathers' emotionality and tactics in marital conflict in the home. Journal of Family Psychology. 2002;16(4):478-92.

52. Lamb M. The Role of the Father in Child Development, (4th Edition). Hoboken NJ: Wiley. 2004.

53. Marmorstein N, Malone S, Iacono W. Psychiatric Disorders Among Offspring of Depressed Mothers: Associations With Paternal Psychopathology. American Journal of Psychiatry. 2004;161(9):1588 - 94.

54. Roebuck TM, Mattson SN, Riley EP. Behavioral and psychosocial profiles of alcoholexposed children. Alcoholism: Clinical and Experimental Research. 1999;23(6):1070-6. 
55. Chatterji P, Markowitz S. The impact of maternal alcohol and illicit drug use on children's behavior problems: evidence from the children of the national longitudinal survey of youth. Journal of Health Economics. 2001 Sep;20(5):703-31.

56. Altink ME, Slaats-Willemse DI, Rommelse NN, Buschgens CJ, Fliers EA, AriasVasquez A, et al. Effects of maternal and paternal smoking on attentional control in children with and without ADHD. European Child \& Adolescent Psychiatry. 2009 Aug;18(8):465-75.

57. Stuart GL, Moore TM, Kahler CW, Ramsey SE, Strong D. Cigarette smoking and substance use among men court-referred to domestic violence treatment programs. American Journal on Addictions. 2004 May;13(3):319-20.

58. Stuart GL, Meehan J, Moore TM, Hellmuth J, Morean M, Follansbee K. Readiness to quit cigarette smoking, violence and psychopathology among arrested domestically violent men. American Journal on Addictions. 2006 01;15(3):256-7.

59. Briggs-Gowan MJ, Carter AS, Skuban EM, Horwitz SM. Prevalence of socialemotional and behavioral problems in a community sample of 1- and 2-year-old children. Journal of the American Academy of Child \& Adolescent Psychiatry. 2001 Jul;40(7):811-9.

60. Becker K, El-Faddagh M, Schmidt MH, Esser G, Laucht M. Interaction of dopamine transporter genotype with prenatal smoke exposure on ADHD symptoms. Journal of Pediatrics. 2008;152(2):263-9.

61. Bronfenbrenner U, Evans G. Developmental Science in the 21st Century: Emerging questions, theoretical models, research design and empirical findings. Social Development (Blackwell Publishing UK). 2000;9(1):115 - 25. 
Cornforth et al., Determinants of Emotional and Behavioural Difficulties in SGA Children

62. Fergusson DM, Horwood J, Lynskey M. Children and Adolescents. Health NZMo, editor. Wellington, NZ1997. 
Table I. Frequencies, simple and adjusted odds ratios for variables measured at a child's birth and age 3.5 years associated with preschool behavioural problems in the total study group.

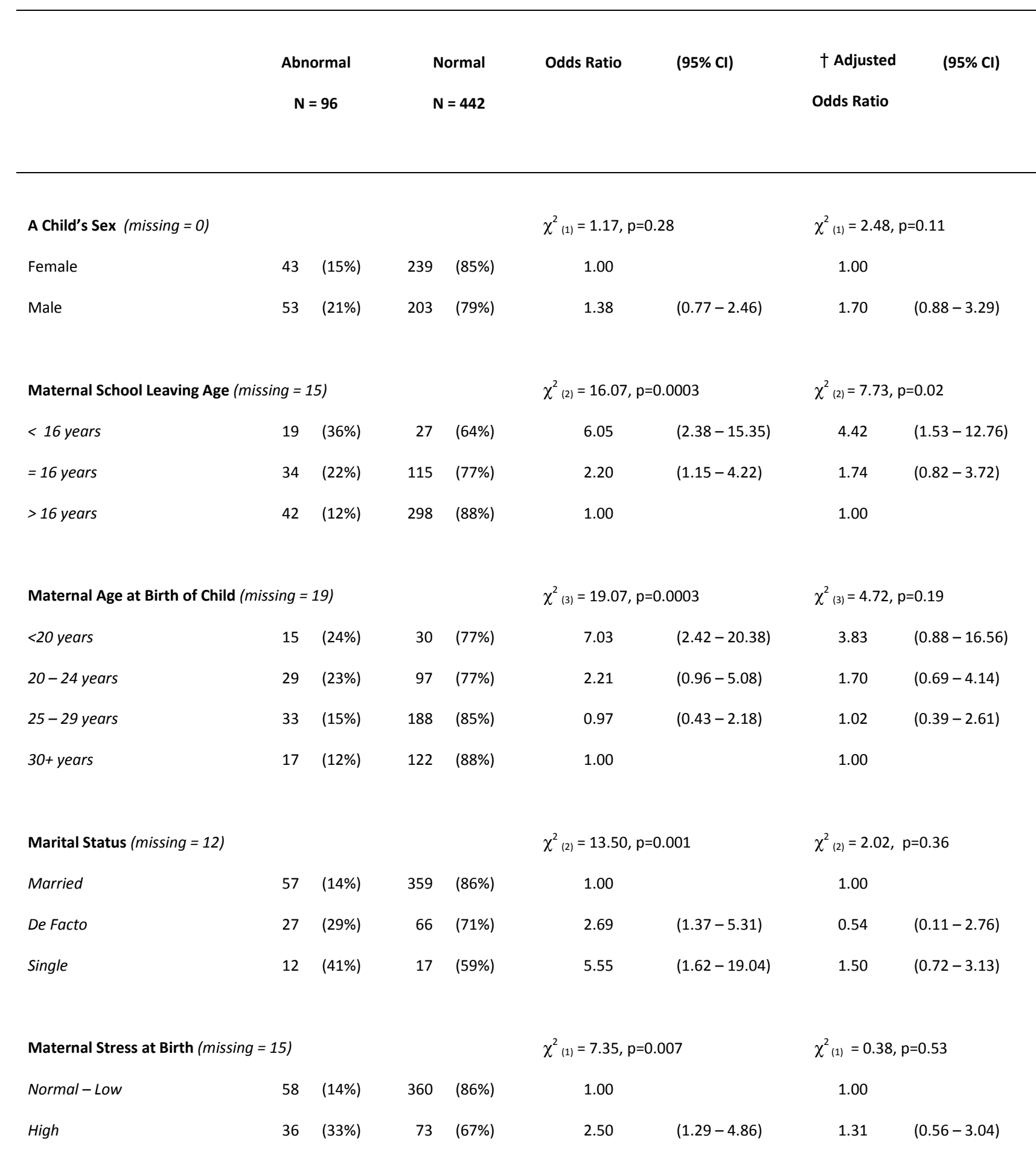


Cornforth et al., Determinants of Emotional and Behavioural Difficulties in SGA Children

Maternal Stress at 3.5 Years (missing $=14$ )

Normal - Low

High

$56(87 \%)$

$39(37 \%)$

$(13 \%)$

(63\%)

Maternal Social Support at Birth (missing $=12$ )

Normal - High

$65(16 \%)$

31 (21\%)

Low

Maternal Social Support at 3.5 Years (missing $=12$ )

Normal - High

$52(15 \%)$

$44 \quad(23 \%)$

Low

Maternal Smoking prior to pregnancy (missing $=15$ )

No

$34(12 \%)$

$62(25 \%)$

253

Yes

Paternal Smoking (missing = 17)

$\begin{array}{lllll}\text { No } & 48 & (12 \%) & 343 & (88 \%) \\ \text { Yes } & 48 & (34 \%) & 94 & (66 \%)\end{array}$

Maternal Alcohol Use in Pregnancy (missing = 15)

O units/week

1-7 units/week

$>7$ units/week

$34(14 \%)$

$53(19 \%)$

$9 \quad(36 \%)$

Biological Father living at Home at 3.5 Years (missing $=14$ )

$\begin{array}{lllll}\text { Yes } & 69 & (15 \%) & 407 & (85 \%) \\ \text { No } & 27 & (45 \%) & 33 & (55 \%)\end{array}$

Child Activity Level at 3.5 Years (missing $=15$ )

More Active

$38 \quad(21 \%)$

140

Same / Less Active

$58 \quad(16 \%) \quad 29$

$$
\chi_{(1)}^{2}=14.02, p=0.0002
$$

1.00

3.41

$(1.79-6.47)$

$\chi_{(1)}^{2}=4.13, p=0.04$

1.00

1.88

$(1.02-3.47)$

$\chi_{(1)}^{2}=4.77, p=0.03$

1.00

1.93

$(1.07-3.48)$

$\chi_{(1)}^{2}=18.36, p<0.0001$

1.00
$3.69 \quad(2.03-6.71)$

$\chi_{(1)}^{2}=16.98, p<0.0001$

1.00

3.64

$(2.00-6.73)$

$\chi_{(2)}^{2}=6.68, p=0.04$

1.00

1.32

4.52

$(0.72-2.45)$

$(1.44-14.22)$

$\chi_{(1)}^{2}=19.72, p<0.0001$

1.00

6.76

$(2.91-15.70)$

$\chi_{(1)}^{2}=4.39, p=0.04$

(79\%)

(87\%)

$1.88 \quad(1.04-3.39)$

$\chi_{(1)}^{2}=5.85, p=0.02$

1.00

$2.48 \quad(1.19-5.17)$

$\chi_{(1)}^{2}=3.42, p=0.06$

1.00

$1.98 \quad(0.96-4.09)$

$\chi_{(1)}^{2}=1.83, p=0.17$

1.00

$1.65(0.79-3.41)$

$\chi_{(1)}^{2}=4.51, p=0.03$

1.00

$2.01 \quad(1.06-4.15)$

$\chi_{(1)}^{2}=4.27, p=0.04$

1.00

$2.21 \quad(1.04-4.68)$

$\chi_{(2)}^{2}=7.97, p=0.02$

1.00

$1.51 \quad(0.75-3.08)$

$6.13 \quad(1.73-21.65)$

$\chi_{(1)}^{2}=4.49, p=0.03$

1.00

$3.11 \quad(1.09-8.89)$

$\chi_{(1)}^{2}=4.76, p=0.03$

$2.13(1.06-4.31)$

1.00 
Cornforth et al., Determinants of Emotional and Behavioural Difficulties in SGA Children

$†$ Multiple regression odds ratio reported adjusts for the effects of child's sex; maternal age at the child's birth; maternal school leaving age; parental marital status at birth; maternal smoking prior to pregnancy; maternal alcohol use during pregnancy; paternal smoking; living with the child's biological father at 3.5 years and child physical activity levels at age 3.5 years. 
Table II. Frequencies and interaction $p$ values for variables measured at a child's birth and age 3.5 years associated with preschool behavioural problems in the SGA and AGA groups.

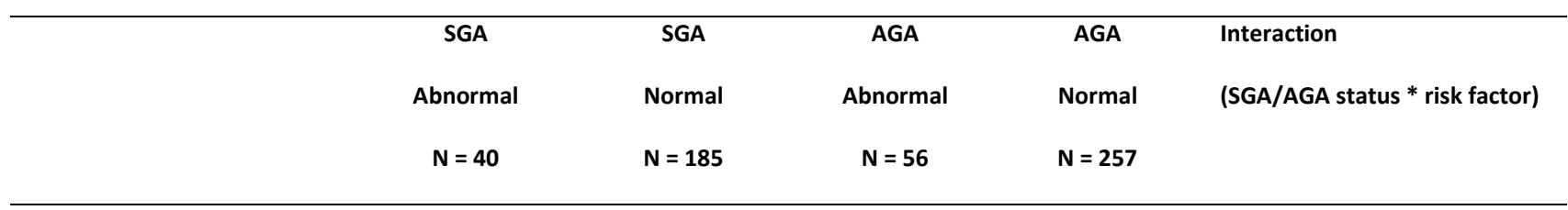

A Child's Sex

Female

Male

$18(15 \%)$

$22(21 \%)$
104

$81(79 \%)$

Maternal School Leaving Age

$<16$ years

$=16$ years

$>16$ years

Maternal Age at Birth of Child

$<20$ years

$20-24$ years

$25-29$ years

$30+$ years

Marital Status

Married

De Facto

Single

Maternal Stress at Birth

Normal-Low

High

$\begin{array}{rrrr}9 & (36 \%) & 16 & (64 \%) \\ 12 & (18 \%) & 53 & (82 \%) \\ 18 & (13 \%) & 116 & (87 \%)\end{array}$

$18(13 \%)$

(87\%)

$6 \quad(11 \%)$

(89\%)
$22 \quad(13 \%)$

$10 \quad(26 \%)$

$8 \quad(40 \%)$

$12(60 \%)$

$20 \quad(12 \%)$

$148(88 \%)$

$34 \quad(63 \%)$

$10 \quad(47 \%)$

$22(26 \%)$

$11 \quad(52 \%)$

$\chi_{(2)}^{2}=0.44, p=0.80$

$24 \quad(12 \%)$

$62(74 \%)$

$182 \quad(88 \%)$

$\begin{array}{rrrrrrrr}6 & (23 \%) & 20 & (77 \%) & 9 & (47 \%) & 10 & (53 \%) \\ 11 & (22 \%) & 40 & (78 \%) & 18 & (24 \%) & 57 & (76 \%) \\ 15 & (16 \%) & 77 & (84 \%) & 18 & (14 \%) & 111 & (86 \%) \\ 6 & (11 \%) & 47 & (89 \%) & 11 & (13 \%) & 75 & (87 \%)\end{array}$

$38 \quad(15 \%)$

$16(29 \%)$
212 (85\%)

$39 \quad(71 \%)$ 
Cornforth et al., Determinants of Emotional and Behavioural Difficulties in SGA Children

Maternal Stress at $\mathbf{3 . 5}$ years

$\begin{array}{llllllllll}\text { Normal - Low } & 20 & (11 \%) & 157 & (88 \%) & 36 & (14 \%) & 215 & (86 \%) & \chi_{(1)}^{2}=2.23, \mathrm{p}=0.13 \\ \text { High } & 19 & (41 \%) & 27 & (58 \%) & 20 & (34 \%) & 39 & (66 \%)\end{array}$

Maternal Smoking Prior to Pregnancy

$\begin{array}{llllllllll}\text { No } & 13 & (13 \%) & 86 & (87 \%) & 21 & (11 \%) & 167 & (89 \%) & \chi_{(1)}^{2}=2.95, \mathrm{p}=0.09 \\ \text { Yes } & 27 & (22 \%) & 97 & (78 \%) & 35 & (28 \%) & 89 & (72 \%)\end{array}$

Paternal Smoking

$\begin{array}{llllllllll}\text { No } & 16 & (11 \%) & 132 & (89 \%) & 32 & (13 \%) & 211 & (87 \%) & \chi_{(1)}^{2}=0.31, p=0.58 \\ \text { Yes } & 21 & (32 \%) & 50 & (68 \%) & 24 & (35 \%) & 44 & (65 \%)\end{array}$

Maternal Alcohol Use in Pregnancy

\begin{tabular}{|c|c|c|c|c|c|c|c|c|c|}
\hline O units/week & 13 & $(14 \%)$ & 82 & $(86 \%)$ & 21 & $(15 \%)$ & 120 & $(85 \%)$ & $\chi_{(2)}^{2}=4.26, p=0.12$ \\
\hline 1-7 units/week & 24 & $(21 \%)$ & 93 & $(79 \%)$ & 29 & $(18 \%)$ & 128 & $(81 \%)$ & \\
\hline > 7 units/week & 3 & $(27 \%)$ & 8 & $(73 \%)$ & 6 & $(43 \%)$ & 8 & (57\%) & \\
\hline
\end{tabular}

Biological Father living at Home at 3.5 Years

$\begin{array}{llllllllll}\text { Yes } & 24 & (13 \%) & 161 & (87 \%) & 45 & (15 \%) & 246 & (85 \%) & \chi_{(1)}^{2}=1.17, p=0.28 \\ \text { No } & 16 & (41 \%) & 23 & (59 \%) & 11 & (52 \%) & 10 & (48 \%)\end{array}$

Child Activity Level at 3.5 Years

$\begin{array}{lllllllll}\text { More Active } & 17 & (20 \%) & 66 & (80 \%) & 17 & (20 \%) & 66 & (80 \%) \\ \text { Same / Less Active } & 23 & (16 \%) & 117 & (84 \%) & 23 & (16 \%) & 117 & (84 \%)\end{array}$

Maternal Social Support at Birth

$\begin{array}{lccccccccc}\text { Normal }- \text { High } & 31 & (19 \%) & 135 & (81 \%) & 34 & (15 \%) & 193 & (85 \%) & \chi_{(1)}^{2}=1.59, \mathrm{p}=0.21 \\ \text { Low } & 9 & (15 \%) & 50 & (85 \%) & 22 & (26 \%) & 64 & (74 \%)\end{array}$

Maternal Social Support at 3.5 Years

$\begin{array}{llllllllll}\text { Normal }- \text { High } & 20 & (15 \%) & 115 & (85 \%) & 32 & (15 \%) & 179 & (85 \%) & \chi_{(1)}^{2}=0.11, p=0.74 \\ \text { Low } & 20 & (22 \%) & 70 & (8 \%) & 24 & (24 \%) & 78 & (76 \%)\end{array}$


Cornforth et al., Determinants of Emotional and Behavioural Difficulties in SGA Children

$\dagger$ Interaction between SGA/AGA status and risk factor examined in multiple regression model including a child's sex; maternal age at the child's birth; maternal school leaving age; parental marital status at birth; maternal smoking prior to pregnancy; maternal alcohol use during pregnancy; paternal smoking; maternal stress at age 3.5 years; living with the child's biological father at 3.5 years and child physical activity levels at age 3.5 years 